\title{
Aplikasi Virtual Tour Sekolah Menengah Pertama (SMP) Negeri 3 Kota Pagar Alam Berbasis Android
}

\author{
Putri Utami ${ }^{1}$, Jemakmun ${ }^{2}$ \\ 1,2Informatics Departement, Bina Darma University, Palembang, Indonesia \\ Email: putriu669@gmail.com¹, jemakmun@binadarma.ac.id ${ }^{2}$
}

\begin{abstract}
Technological developments are increasingly rapid, giving rise to many new innovations from technology such as virtual tours. Virtual tour is one of the information media that displays $360^{\circ}$ panoramic images in visual form. However, the use of virtual tour applications as a promotional medium and introduction to the school environment is still very little. In this study, the author makes a virtual tour application to help parties from SMP Negeri 3 Kota Pagar Alam in promoting and introducing the virtual school environment. The application development method used in this study is the Multimedia Development Life Cycle (MDLC) which consists of six stages of multimedia development, namely Concept, Design, Material Collecting, Assembly, Tasting, and Destribution. The tools used in this research are Unity 3D, Google Street View Application. The tools used in the development are Use Case Diagrams, and Activity Diagrams. With the formation of this virtual tour application, it can make it easier for all students, teachers and the wider community to see the environment of SMP Negeri 3 Pagar Alam City virtually.
\end{abstract}

Keywords: SMP Negeri 3, Virtual Tour, Meltimedia Development Life Cycle (MDLC), Unity 3D, UML (Unified Modelling Language)

\section{PENDAHULUAN}

Virtual Tour merupakan sebuah simulasi dari sebuah lokasi yang terdiri dari gabungan gambar panorama yang saling berhubungan dan menampilkan dengan sudut pandang $360^{\circ} \times 180^{\circ}$. Virtual tour sendiri biasanya digunakan untuk memberi pengalaman "pernah ada" disuatu tempat hanya melihat layar monitor yang akan menampilkan tampak nyata area dari SMP Negeri 3 Kota Pagar Alam dalam bentuk foto panorama dengan sudut pandang $360^{\circ} \times 180^{\circ}$. Virtul Tour ini membuat pengguna seakan-akan berada langsung dalam lingkungan SMP Negeri 3 Kota Pagar Alam tersebut.

Sekolah Menengah Pertama (SMP) Negeri 3 Kota Pagar Alam merupakan salah satu sekolah negeri yang ada di Kota Pagar Alam, didirikan pada tahun 1984 terletak di JIn. Persirah Lembah Kelurahan Bumi Agung, tahun 1984 terletak 


\section{Journal of Software Engineering Ampera}

Vol. 2, No. 3, October 2021 e-ISSN: 2775-2488

https://journal-computing.org/index.php/journal-sea/index

di JIn. Persirah Lembah Kelurahan Bumi Agung, Kecamatan Dempo Utara, Kota Pagar Alam. Media informasi SMP Negeri 3 saat ini dinilai masih kurang dalam memperkenalkan atau mempromosikan lingkungan sekolah karena masih menggunakan media yang konvensional atau manual seperti media cetak, brosur dan lainnya sehingga tingkat keefektifanya masih rendah. Karena pihak dari SMP Negeri 3 Kota Pagar Alam belum menyediakan media informasi dalam bentuk Virtual yang dapat memperkenalkan atau mempromosikan lingkungan sekolah dengan menggambarkan sekolah secara nyata seperti kita berada langsung di sekolah tersebut. Oleh karna itu penulis tertarik melakukan penelitian pada SMP Negeri 3 Kota Pagar Alam untuk mengatasi permasalahan yang dihadapi.

Berdasarkan permasalahan yang dihadapi maka penulis akan membuat media penyampaian informasi mengenai lingkungan sekolah dengan menggunakan konsep Virtul Tour guna mempromosikan lingkungan SMP Negeri 3 Kota Pagar Alam ke masyarakat luas.

\section{METODE PENELITIAN}

Dalam melakukan penelitian penulis menggunakan metode pengembangan aplikasi yaitu metode MDLC (Multimedia Development Life Cycle) yang terdiri dari 6 tahapan meeliputi Concept, Design, Material Collecting, Assembly, Testing, dan Distribution yang dilakukan tidak harus berurutan dalam pratiknya, artinya dapat saling bertukar posisi, namun tahapan konsep haruslah menjadi yang pertama dikerjakan.

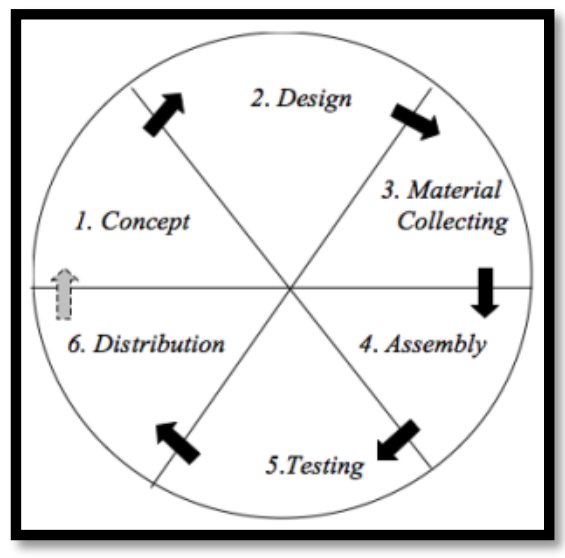

Gambar 1 Model MDLC (Multimedia Development Life Cycle) 


\section{Journal of Software Engineering Ampera}

Vol. 2, No. 3, October 2021 e-ISSN: 2775-2488

https://journal-computing.org/index.php/journal-sea/index

\subsection{Concept}

Pada tahap pengonsepan ini adalah awal dari perancangan multimedia yang menggunakan metode MDLC ada dua tahap yang perlu diperhatikan, antara lain menentukan tujuan aplikasi yaitu untuk memperkenalkan atau mempromosikan lingkungan sekolah guna mempermudah siswa dan masyarakat umum dalam mencari informasi mengenai lingkungan SMP Negeri 3 Kota Pagar Alam. Aplikasi ini digunakan untuk media pengenalan lingkungan di SMP Negeri 3 Kota Pagar Alam yang dioperasikan pada perangkat bersistem operasi android.

Table 1 Konsep Multimedia Interaktif

\begin{tabular}{|c|l|}
\hline Judul & $\begin{array}{l}\text { Aplikasi Virtual Tour Sekolah Menengah Pertama } \\
\text { (SMP) Negeri 3 Kota Pagar Alam Berbasis Android }\end{array}$ \\
\hline Tujuan & $\begin{array}{l}\text { Membuat sebuah aplikasi virtual tour yang dapat } \\
\text { memperkenalkan atau mempromosikan lingkungan } \\
\text { sekolah guna memper mudah siswa dan dan guru } \\
\text { khususnya masyarakat luas dalam memcari informasi } \\
\text { mengenai lingkungan SMP Negeri 3 Kota Pagar Alam }\end{array}$ \\
\hline Image & $\begin{array}{l}\text { Menggunakan format file JPG yang dibuat untuk } \\
\text { aplikasi }\end{array}$ \\
\hline Pengguna akhir & Siswa dan Masyarakat Umum \\
\hline Input & Foto dan Teks \\
\hline Output & Foto $360^{\circ}$ dan Teks \\
\hline
\end{tabular}

\subsection{Design}

Pada tahap desain ini membuat rancangan sistem dari sebuah aplikasi. Dengan menggunakan model UML (Unified Modeling Language) yang digambarkan dalam bentuk Use Case Diagram. Pada gambar 2 merupakan use case diagram dimana user dapat mengakses empat menu utama yaitu mulai, tentang sekolah, fasilitas sekolah, dan button keluar. 


\section{Journal of Software Engineering Ampera}

Vol. 2, No. 3, October 2021 e-ISSN: 2775-2488

https://journal-computing.org/index.php/journal-sea/index

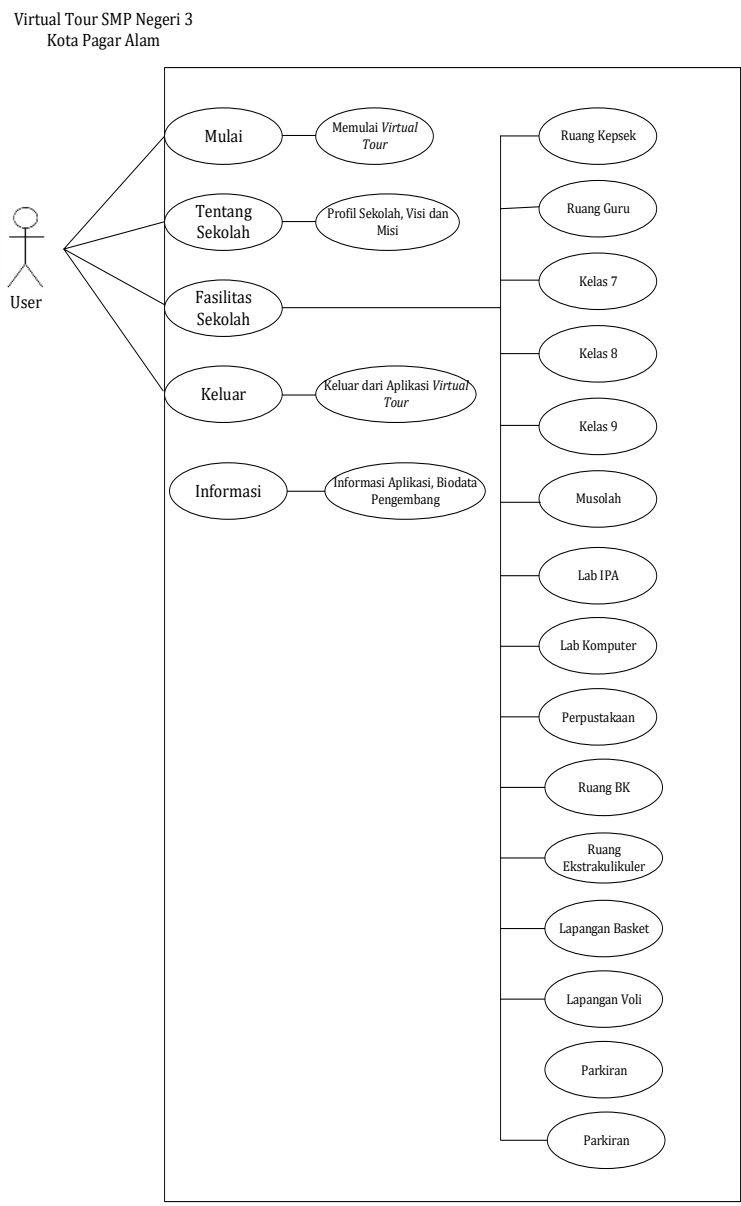

Gambar 2 Use case diagram

\subsection{Material Collection}

Pada tahap material collecting adalah tahap pengumpulan data untuk pembuatan aplikasi virtual tour ini. Bahan yang dibutuhkan berupa gambar yang diambil dari beberapa lokasi yang akan dimasukkan kedalam aplikasi virtual tour. Selain itu pada penelitian ini, disiapkan kebutuhan hardware dan software yang digunakan untuk membangun aplikasi.

\section{HASIL DAN PEMBAHASAN}

Tahap hasil penelitian merupakan hasil yang telah dilakukan secara sistematis. Hasil dari penelitian ini didapat setelah tahap perancangan dan 


\section{Journal of Software Engineering Ampera}

Vol. 2, No. 3, October 2021 e-ISSN: 2775-2488

https://journal-computing.org/index.php/journal-sea/index

pembuatan media dianggap sudah selesai. Hasil dari penelitian ini adalah sebuah aplikasi virtual tour yang dapat di akses pada android oleh user. Berikut adalah hasil dari penelitian yang mengacu pada metode MDLC sebagai berikut.

\subsection{Hasil Tahap Material Collecting}

Tahap material collecting ini adalah tahap pengumpulan data yang akan digunakan untuk pembuatan aplikasi virtual tour SMP Negeri 3 Kota Pagar Alam. Dalam hal ini bahan-bahan yang digunakan berupa foto $360^{\circ}$ area SMP Negeri 3 Kota Pagar Alam yang diambil dengan menggunakan kamera Google Street View seperti gambar berikut.

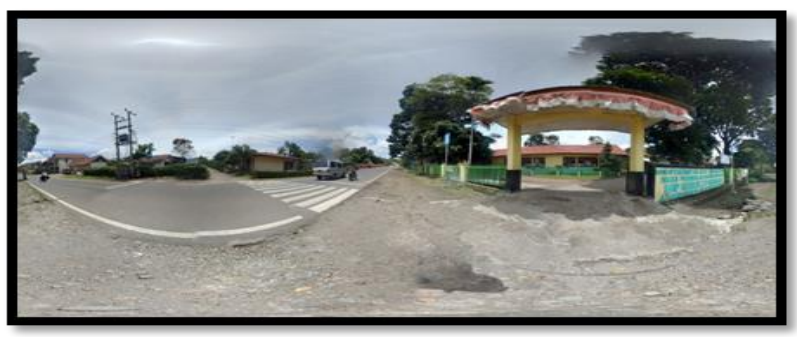

Gambar 4 Hasil foto bagian gerbang SMP Negeri 3

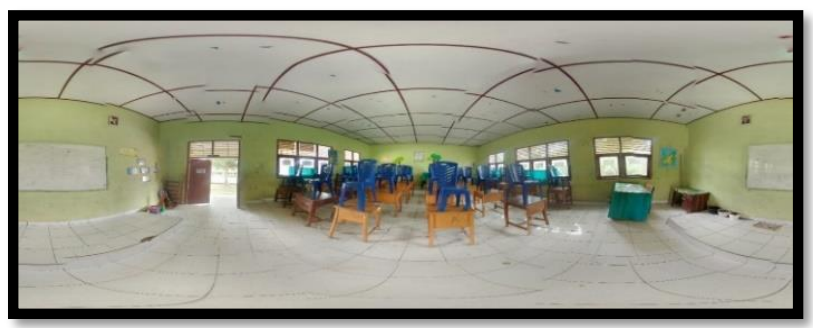

Gambar 5 Hasil foto ruang kelas

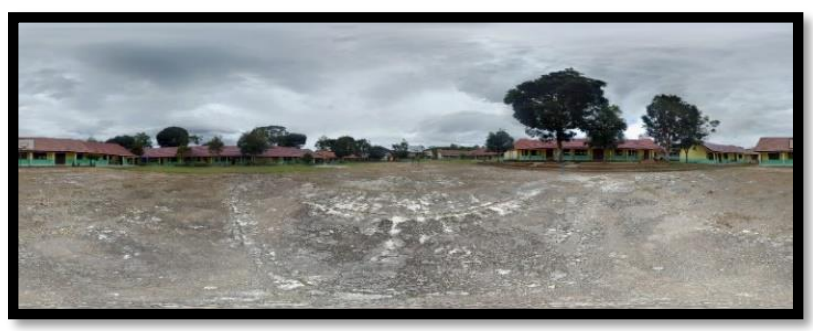

Gambar 6 hasil foto area lapangan 


\section{Journal of Software Engineering Ampera}

Vol. 2, No. 3, October 2021 e-ISSN: 2775-2488

https://journal-computing.org/index.php/journal-sea/index

\subsection{Hasil Proses Tahap Assembly}

Tahap assembly adalah tahap pembuatan aplikasi yang telah di desain sebelumnya dengan menggunakan semua data yang telah dikumpulkan. Tahap ini juga dilakukan pembangunan aplikasi dengan menggunakan tools unity 3D 2018 dan pemprogramannya menggunakan tools visual studio 2017.

1. Pembangunan Menu Utama

Pada tahap ini dilakukan pembangun menu utama yang telah didesain sebelumnya dengan menggunakan Unity 3D seperti pada gambar sebagai berikut.

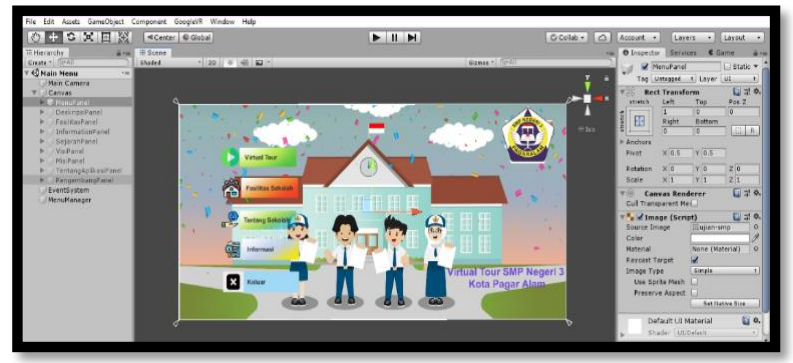

Gambar 7 Proses pembuatan menu utama

\section{Pembangunan Menu Virtual Tour}

Pada tahap pembangun menu virtual tour ini dilakukan pembuatan sphere-sheper untuk menempatkan foto-foto $360^{\circ}$ yang telah dikumpulkan sebelumnya. Seperti pada gambar 9 berikut.

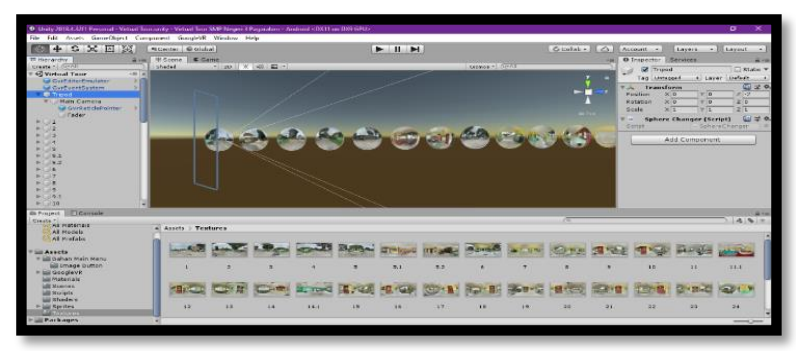

Gambar 8 Proses pembuatan menu virtual tour

\section{Pembangunan Menu Tentang Sekolah}

Pembangunan menu tentang sekolah dimana pada tahap ini dilakukan pembuatan button sejarah sekolah, button visi sekolah, dan button misi sekolah seperti pada gambar dibawah ini. 


\section{Journal of Software Engineering Ampera}

Vol. 2, No. 3, October 2021 e-ISSN: 2775-2488

https://journal-computing.org/index.php/journal-sea/index

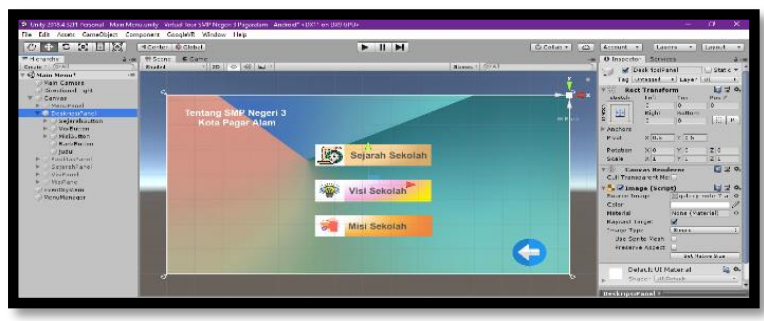

Gambar 9 Proses pembuatan menu tentang sekolah

\section{Pembangunan Menu Fasilitas Sekolah}

Pada gambar 8 dibawah ini adalah tahap pembuatan menu fasilitas sekolah yang terdiri dari 15 button antara lain ruang kepalah sekolah, ruang guru, ruang kelas 7 , ruang kelas 8 , ruang kelas 9, musholah, laboratorium ipa, laboratorium komputer, perpustakaan, ruang bk, ruang ekstrakulikuler, lapangan basket, lapangan voli, parkiran dan ruang kesenian.

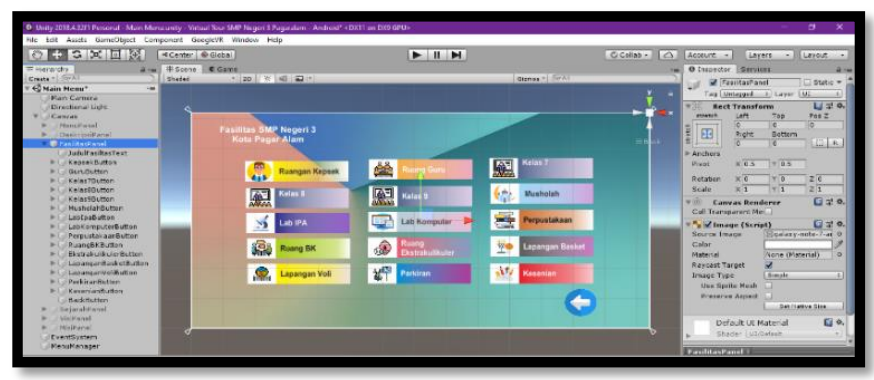

Gambar 10 Proses pembuatan menu fasilitas sekolah

\subsection{Tahap Testing}

Pengujian yang dilakukan dengan menggunakan pendekatan blackbox testing, yaitu dengan menjalankan aplikasi/program dan melihat apakah ada kesalahan atau tidak. Hasil pengujian yang dilakukan adalah aplikasi ini bisa berjalan dengan baik, serta tombol-tombol yang terdapat pada aplikasi bisa berfungsi sesuai tujuan.

1. Tampilan menu utama pada aplikasi virtual tour

Halaman utama pada aplikasi virtual tour adalah halaman yang pertama kali dimunculkan saat aplikasi dibuka, yang menampilkan menu virtual tour, tentang sekolah, fasilitas sekolah, menu informasi dan tombol keluar. 


\section{Journal of Software Engineering Ampera}

Vol. 2, No. 3, October 2021 e-ISSN: 2775-2488

https://journal-computing.org/index.php/journal-sea/index

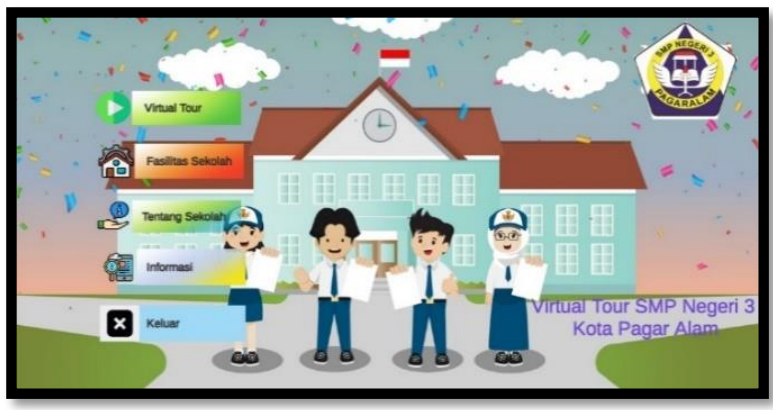

Gambar 11 Tampilan menu utama

2. Tampilan menu virtual tour

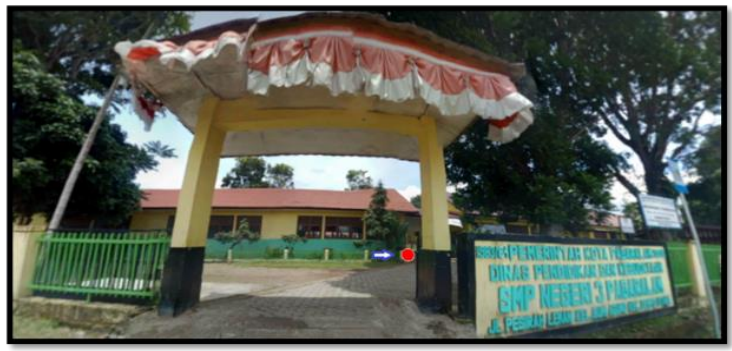

Gambar 12 Tampilan gerbang SMP pada Menu virtual tour

Halaman menu virtual tour adalah halaman yang menampilkan seluruh bagian yang ada di SMP Negeri 3 Kota Pagar Alam secara virtual, dimulai dari gerbang sekolah sampai dengan lapangan sekolah. Berikut adalah tampilan dari menu virtual tour dengan contoh foto gerbang sekolah

3. Tampilan menu tentang sekolah

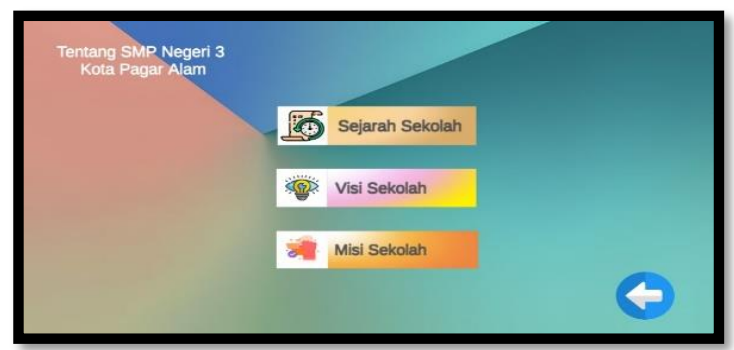

Gambar 13 Tampilan menu tentang sekolah 


\section{Journal of Software Engineering Ampera}

Vol. 2, No. 3, October 2021 e-ISSN: 2775-2488

https://journal-computing.org/index.php/journal-sea/index

Menu tentang sekolah adalah menu yang menampilkan tentang sekolah SMP Negeri 3 Kota Pagar Alam secara singkat, pada menu ini terdapat tiga button yang dapat dipilih oleh user, meliputi sejarah sekolah, visi dan misi sekolah.

4. Tampilan menu fasilitas sekolah

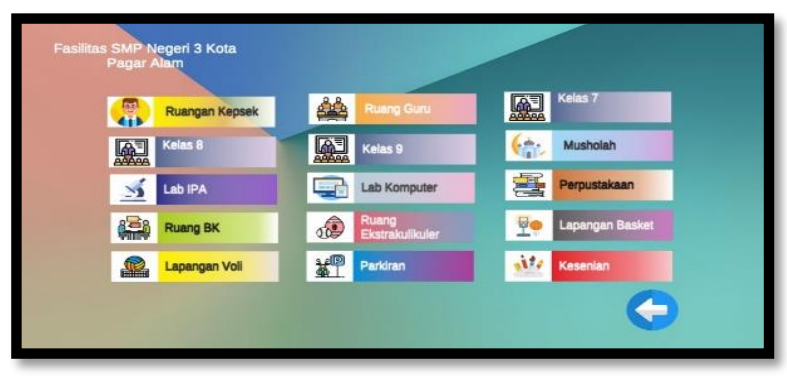

Gambar 14 tampilan menu fasilitas sekolah

\subsection{Distribution}

Tahap distribution merupakan tahap terakhir dalam metode MDLC. Pada tahap ini aplikasi dipublikasikan dan dipromosikan untuk user atau siswa dan masyarakat umum. Aplikasi yang sudah dianggap layak dan sudah memiliki izin dari tempat penelitian akan dipublikasikan secara umum dengan cara mengupload ke Google Playstore agar dapat diakses oleh user.

\section{KESIMPULAN}

Sebagai kesimpulan dari penulisan skripsi ini adalah sebagai berikut:

1. Aplikasi Virtual Tour SMP Negeri 3 Kota Pagar Alam dibuat sebagai media pengenalan dan media promosi lingkungan dari SMP Negeri 3.

2. Virtual tour ini telah dibuat sesuai dengan rancangan, yaitu dapat menampilkan bagian outdoor maupun indoor SMP Negeri 3 Kota Pagar Alam

3. Virtual tour ini telah diuji menggunakan metode pendekatan black box dan hasilnya semua dapat berjalan dengan rancangannya.

4. Virtual tour dapat diinstall dan digunakan pada smartphone.

\section{DAFTAR PUSTAKA}

[1] Rivai, Dani Ainur, Sukandi (2013) 'Pembuatan Website Profil Sekolah Menengah Kejuruan (Smk) Miftahul Huda Ngadirojo', 2(3). p.5. 


\section{Journal of Software Engineering Ampera}

Vol. 2, No. 3, October 2021 e-ISSN: 2775-2488

https://journal-computing.org/index.php/journal-sea/index

[2] Umafagur, F., Sentinuwo, S. R. and Sugiarso, B. A. (2016) 'Implementasi Virtual Tour Sebagai Media Informasi Daerah (Studi Kasus : Kota Manado)', Jurnal Teknik Informatika, 9(1). doi: 10.35793/jti.9.1.2016.13456.

[3] Wulur, H. W., Sentinuwo, S. and Sugiarso, B. (2015) 'Aplikasi Virtual tour Tempat Wisata Alam di Sulawesi Utara', Jurnal Teknik Informatika, 6(1). doi: 10.35793/jti.6.1.2015.9953.

[4] Sekarwati, K. A., Iqbal, M. and Putri, D. K. (2018) 'Pemanfaatan Fitur Street-View Pada Aplikasi Penginderaan Jarak Jauh (Google Earth) Untuk Identifikasi Jenis Dan Penempatan Rambu Lalu Lintas Sepanjang Jalan Ir. H. Juanda Depok', p. 6.

[5] Universitas Hamzanwadi et al. (2018) 'Pengaruh Aplikasi C\# dalam Proses Perhitungan Numerik Terhadap Solusi Persamaan Non Linier', Infotek: Jurnal Informatika dan Teknologi, 1(2), pp. 79-87. doi: 10.29408/jit.v1i2.901.

[7] Manabung, Suzanna Edith. (2019)'Virtual Tour Foto $360^{\circ}$ Rumah Sakit Umum Pusat Prof. Dr. R. D. Kandou Manado', (2), p. 6.

[8] Umagapi, D. (2017) 'Pembelajaran Photoshop Menggunakan Metode Web Product Based Learning Pada Global Science Institute (Gsi) Ternate', P. 8. 